\title{
A Structural Analysis of Natural Gas Consumption by Income Class from 1987 to 1993
}

by David A. Poyer

Decision and Information Sciences Division,

Argonne National Laboratory, 9700 South Cass Avenue, Argonne, Illinois 60439

Work sponsored by U.S. Department of Energy Office of Economic Impact Diversity

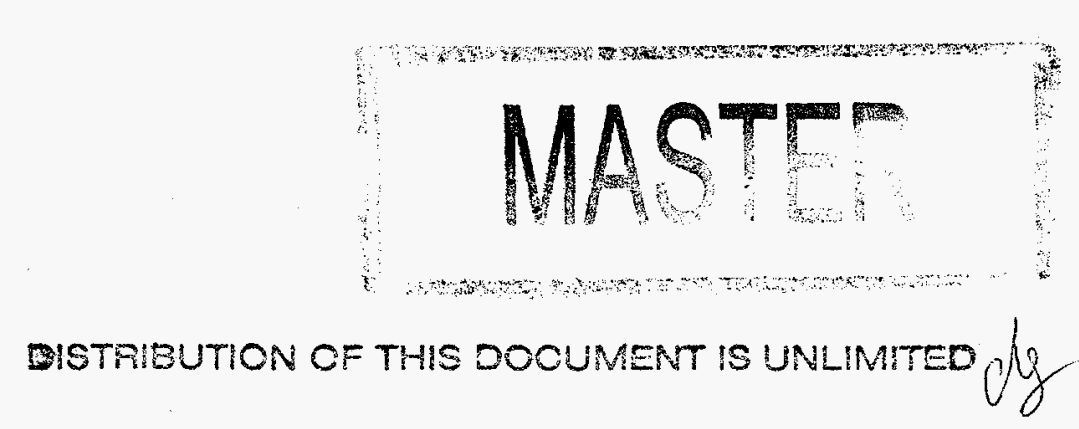


बत्

This report is printed on recycled paper. 


\section{DISCLAMMER}

Portions of this document may be illegible in electronic image products. Images are produced from the best available original document. 


\section{CONTENTS}

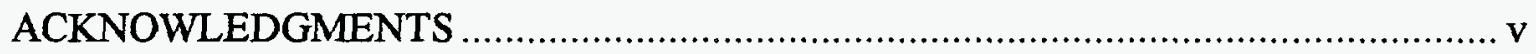

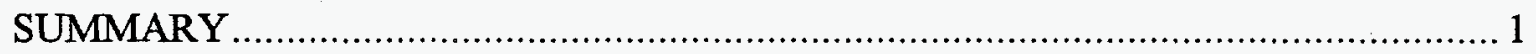

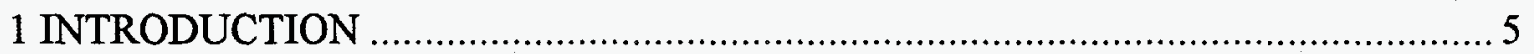

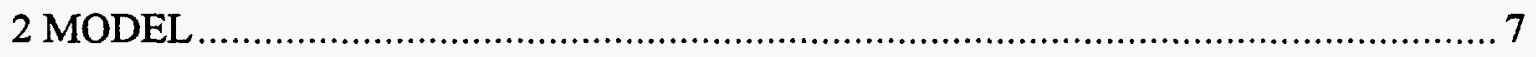

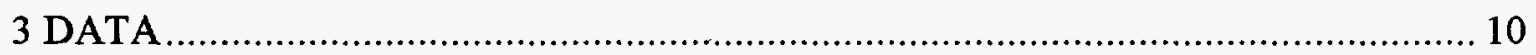

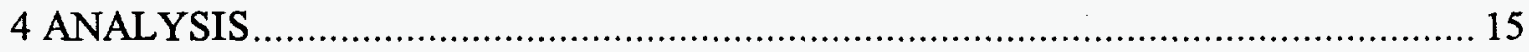

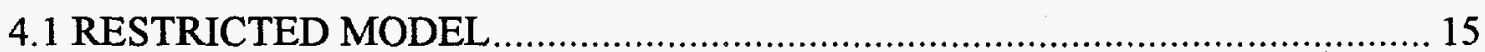

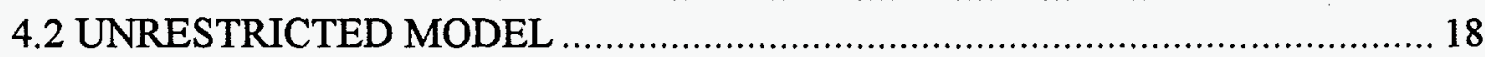

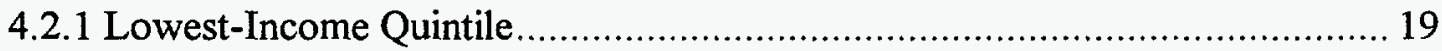

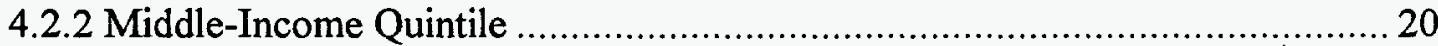

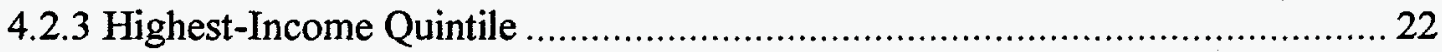

4.2.4 Structural and Variable Decomposition ................................................ 24

4.2.5 Comparative Analysis.................................................................... 28

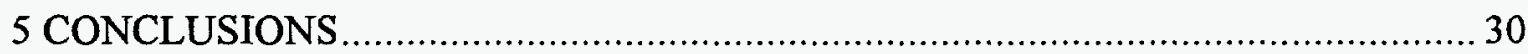

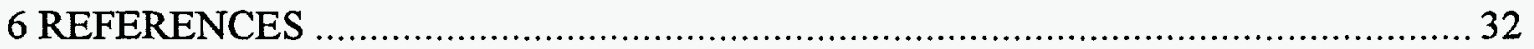

\section{TABLES}

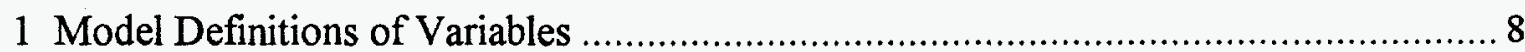

2 Household Population Estimates (thousands of households) and Number of Observations.

3 Average Natural Gas Consumption $\left(10^{6} \mathrm{Btu} / \mathrm{yr}\right.$ per household) .......................... 11

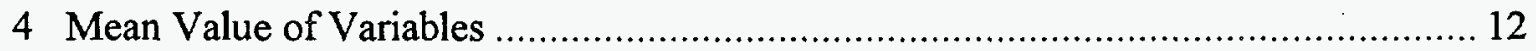

5 Qualitative Changes in Household Natural Gas Consumption and Related Variables . 14

6 Natural Gas Consumption Model Parameter Estimates for the Restricted Model ....... 16 
7 Structural Difference Effects on Natural Gas Consumption: Restricted Model

8 Correlation Matrix of Coefficients

9 Percent Use by End-Use Service Category.

10 Natural Gas Consumption Model Parameter Estimates for the Unrestricted Model: Lowest-Income Quintile

11 Estimated End-Use Consumption Due to Structural Changes:

Lowest-Income Quintile

12 Natural Gas Consumption Model Parameter Estimates for the Unrestricted Model: Middle-Income Quintile.

13. Estimated End-Use Consumption Due to Structural Changes:

Middle-Income Quintile

14 Natural Gas Consumption Model Parameter Estimates for the Unrestricted Model:

Highest-Income Quintile

15 Estimated End-Use Consumption Due to Structural Changes:

Highest-Income Quintile

16 Estimated Percentage Difference in End-Use Consumption

Due to Structural Differences with the Highest-Income Quintile

\section{FIGURES}

S.1 Estimated Average Natural Gas Consumption 2

1 Decomposition of Changes in Natural Gas Consumption: 1987-1990 ...................... 25

2 Decomposition of Changes in Natural Gas Consumption: $1990-1993$.................... 26

3 Decomposition of Changes in Natural Gas Consumption: 1987-1993 


\section{ACKNOWLEDGMENTS}

I would like to extend special thanks to Georgia Johnson of the Office of Economic Impact and Diversity for her continued support of the research reported in this document. I also thank Ed Tanzman, Elizabeth Earl and Leslie Nieves of Argonne National Laboratory; Steve Wade of the U.S. Department of Energy; and Ernie Attah of Clark-Atlanta University, for their valuable review and critique of earlier versions of this document. 


\title{
A STRUCTURAL ANALYSIS OF NATURAL GAS CONSUMPTION BY INCOME CLASS FROM 1987 \\ TO 1993
}

by

\author{
D.A. Poyer
}

\section{SUMMARY}

This study had two major objectives: (1) assess and compare changes in natural gas consumption between 1987 and 1993 by income group and (2) assess the potential influence of energy policy on observed changes in natural gas consumption over time and across income groups. This analysis used U.S. Department of Energy (DOE) data files and involved both the generation of simple descriptive statistics and the use of multivariate regression analysis. The latter helped to estimate changes in natural gas intensity (where such a change implied a change in natural gas consumption with all explanatory variables held constant) between income groups and over time.

The consumption of natural gas by the groups was studied over a six-year period, using three Residential Energy Consumption Surveys (RECS). The results showed that:

- Natural gas use was substantially higher for the highest-income quintile group, compared with that for the two lower-income quintile groups (Figure S.1). Natural gas use was slightly higher, although the difference was not statistically significant, for the middle-income quintile, compared with that for the lowest-income quintile.

- Natural gas consumption declined for the lowest- and middle-income quintiles and increased for the highest-income quintile between 1987 and 1990. Between 1990 and 1993, natural gas consumption increased for the lowest- and middle-income quintiles, while it remained relatively constant for the highest-income quintile.

Statistical analysis of the RECS data indicated varying importance of the explanatory variables and structural effects on these changes by income group and time period.

As expected, natural gas use for space heating was the most important determinant of natural gas consumption. Statistically, this variable was the most strongly related to natural gas use for each income group and in each survey period. Other important explanatory variables were the area heated, the number of heating degree days, and the number of household members. 


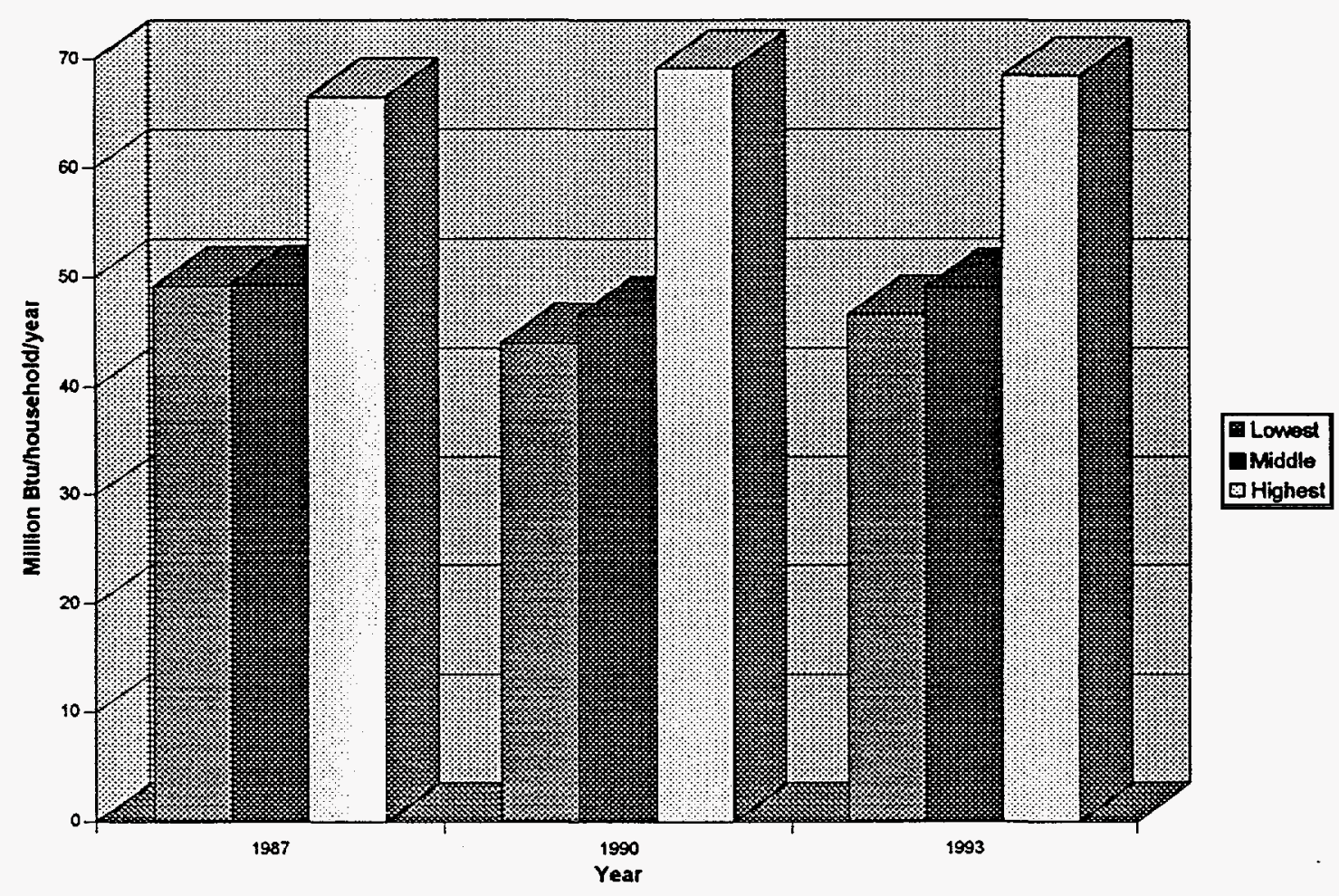

FIGURE S.1 Estimated Average Gas Consumption

Regression analysis of the 1987, 1990, and 1993 RECS data also strongly indicated that the structure of natural gas use differed significantly between income classes and over time:

- The differences in the structure of natural gas use among the three income groups were statistically significant at the 0.005 level.

- The change in the structure of natural gas use between 1987 and 1993 was statistically significant for each income group at the 0.005 level.

- The structure of natural gas use by the lowest-income quintile group was the least stable over time: the percentage deviations from 1990 estimates, particularly for water heating, were large.

- The structure of natural gas use by the middle-income quintile group was the most stable over time. 
The structural shifts in natural gas use were particularly substantial between 1987 and 1990. For the lowest- and middle-income quintiles, the structural shifts reduced natural gas intensity. For the highest-income quintile, the structural shift increased natural gas intensity.

Between 1990 and 1993, the structural changes in natural gas use differed from those between 1987 and 1990. For the lowest- and middle-income quintiles, the structural shifts were very small. For the highest-income quintile, the structural shift was large and reduced natural gas intensity.

The factors driving changes in natural gas consumption between 1987 and 1993 varied for the different income groups. Between 1987 and 1990, for the lowest- and middle-income quintiles, changes were driven by variations in both explanatory variables and structural factors:

- Changes in explanatory variables and structure in natural gas use both contribute to a decrease in natural gas consumption; and

- For the lowest-income quintile, the structural change was relatively more important when compared with that of the middle-income quintile.

For the highest-income quintile, changes were also driven by changes in both explanatory variables and structural factors: changes in the explanatory variables and structure in natural gas use both contributed to an increase in natural gas consumption.

Between 1990 and 1993, for the lowest- and middle-income quintiles, changes were primarily driven by changes in explanatory variables: changes in explanatory variables drove natural gas use up. For the same period, for the highest-income quintile, the fall in natural gas consumption was exclusively driven by changes in the structure of natural gas use, whereas the marginal effect changes in the explanatory variables were positive.

The analysis provides two major energy policy implications:

- Natural gas intensity, although improving, has been the highest for the lowest-income quintile group, indicating that this group is more vulnerable to sudden changes in demand-indicator variables, in particular weather-related variables, that increase natural gas consumption.

- Between 1987 and 1993, the fall in natural gas intensity, particularly for the lowest-income quintile group, may indicate that energy policy possibly the Federal Weatherization Program, local and state energy conservation programs, and higher energy-efficiency performance 
standards (particularly for water heaters) - has had some impact on reducing natural gas consumption. 


\section{INTRODUCTION}

This study estimates the comparative effects of variable changes on household natural gas consumption across income groups and determines how energy policy might differentially affect natural gas use for different income groups, both from a retrospective point of view and looking to the future. The research efforts sought to answer a number of basic questions. Is it safe to assume that the intensity of use of natural gas is the same across income classes? Has it remained constant over time? Also, what implications might be drawn from the data with regard to changes in natural gas intensity? ${ }^{1}$

Recently, the U.S. Department of Energy (DOE) initiated research to develop methods to measure changes in energy efficiency (DOE 1995c). Measuring the effects of changes in the structural use of natural gas was linked to this effort. Furthermore, the use of multivariate regression analysis to measure changes in energy (in this case, natural gas) intensity is an improvement over the univariant measures suggested by DOE (1995c).

DOE's Energy Information Administration (EIA) performed extensive regression analysis of the Residential Energy Consumption Survey (RECS) data. ${ }^{2}$ The primary purpose of this analysis was to produce end-use energy consumption estimates in the individual survey periods. The analysis, however, did not compare estimates across survey-time periods or between population groups.

The consumption of natural gas was studied for three income quintile groups: the lowest-, middle-, and highest-income quintiles. Only three of the five income quintile groups were studied because (1) this method illustrated more sharply the differences in natural gas consumption among income groups; and (2) in terms of practicality, this method expedited the presentation of the analysis. Moreover, analysis by socioeconomic group is particularly relevant, now that the DOE has begun to publish energy expenditure forecasts by income quintile and by race (DOE, 1995b, Table E2, p. 153).

The 1987, 1990, and 1993 RECS data were used in this study. These data made it possible to estimate and compare patterns of natural gas use for each of the three income quintiles.

\footnotetext{
${ }^{1}$ The term intensity, as opposed to efficiency, is used because efficiency improvement implies a change of state in which the consumer is better off. This case would imply that the household could produce the same level of household services with less natural gas while holding prices constant. A change in intensity over time refers to a change in natural gas consumption per household, with all explanatory variables held constant. From the economic point of view, no inference about natural gas efficiency can be made from a change in natural gas intensity. For a description of the concept of intensity, see DOE 1995 c, pp. 3-6.

${ }^{2}$ The end-use estimation methodology is described in the appendices of DOE 1989b, 1993b, and 1995d. For earlier work done on this, see DOE 1983.
} 
The promotion of fairness and equity in the design of energy policy can be greatly helped if differences in energy consumption and expenditure behavior by socioeconomic group are known. Although the analysis presented in this report provides direct means of measuring the effect of policy on economic welfare, it also provides insights and a statistical description of natural gas use that can be used to help design and provide a context for future research with that objective. Moreover, it also provides indirect evidence of the comparative impacts of energy policy on different income groups between 1987 and 1993.

This study incorporated regression analysis to decompose changes in natural gas consumption into variable and structural components, where the structural effects were defined as changes in natural gas consumption attributed to shifts in the parametric relationship between natural gas consumption and its explanatory variables. The presence of structural changes was important in that it indicated changes in natural gas intensity.

The comparative extent and composition of these changes by income class were of specific interest. What does the statistical evidence indicate regarding the comparative level of natural gas consumption and the factors influencing changes in it over time? Do the level and patterns of natural gas use differ among different income classes? Can the differences be used to design better and/or fairer energy policies? 


\section{MODEL}

Natural gas consumption is the sum of natural gas consumption over all household end-use service categories. It is a function of many different factors, such as:

- Meteorological factors

- Heating degree days

- Cooling degree days

- Technological factors

- The home's architectural characteristics

- Amount of insulation

- Composition of energy use across end-use service categories

- Demographic factors, such as the number of household members

- Economic factors

- Prices

- Income.

The influence of a number of these factors on energy consumption overlaps. For example, prices and income are expected to influence natural gas use not only directly but also indirectly (through their influence on household appliance investment decisions).

For this study, an end-use service category was broadly defined. Conceptually, it was viewed as an area of activity where energy is consumed in the production of a set of household services, where the set of household services is variable and not directly defined. For example, within the water-heating, end-use category, energy is used not only to produce water for bathing, but also to produce warm water for recreation (e.g., swimming).

In residential energy consumption, a major fraction of all energy consumption is in the space-heating and water-heating, end-use service categories (DOE 1995e, p. 8). This study estimates natural gas consumption for these two end-use service categories for each of the income groups in each survey time period. 
Conceptually, changes in natural gas consumption were attributed to either changes in explanatory variables or structural shifts in natural gas use (or changes in natural gas intensity). In order to determine the relative importance of these factors, two linear models were estimated for each income class. For each of the models, variables that were intended to capture the effect of space-heating load and water-heating loads on natural gas consumption were included in the set of linear regressors. The model is as follows:

$$
q_{n g, t}=\sum_{i=0}^{n} \alpha_{i, t} x_{i, t}+\varepsilon_{t}
$$

where $q_{n g, t}=$ household natural gas consumption in period $\mathrm{t}\left(10^{6} \mathrm{Btu} / \mathrm{yr}\right.$ per household).

$\alpha_{i, t}=$ coefficient of the ith variable or demand indicator in period $t$,

$x_{i, t}=\mathrm{i}$ th variable or natural gas demand indicator in period $t$,

$n=$ number of independent variables, and

$\varepsilon_{t}=$ disturbance term.

The disturbance term was assumed to be normal, independent, and identically distributed. The definitions of the model variables are shown in Table 1.

TABLE 1 Model Definitions of Variables

\begin{tabular}{|c|c|}
\hline Variable & Definition \\
\hline$q_{n g}$ & Natural gas consumption $\left(10^{6} \mathrm{Btu} / \mathrm{yr}\right.$ per household) \\
\hline const & Constant term \\
\hline ng_heat & Dummy variable indicating natural gas use for space heating \\
\hline space_I & $\begin{array}{l}\text { Space-heating load variable: } n g \text { heat, heating degree days, and area } \\
\text { heated }\left({ }^{\circ} \mathrm{F} \times \mathrm{ft}^{2}\right)\end{array}$ \\
\hline space_2 & space_I $I \times$ number of household members \\
\hline space_3 & space $1 \times$ (number of household members) ${ }^{2}$ \\
\hline$n g h \overline{2 o}$ & Dummy variable indicating natural gas use for water heating \\
\hline water_l & Water-heating load: $n g \_h 2 o$ and number of household members \\
\hline water 2 & water $I \times(\text { number of household members })^{2}$ \\
\hline water_3 & water_I $I \times$ heating degree days \\
\hline singfam & Single-family home \\
\hline
\end{tabular}

The variables that include the natural gas end-use dummy variables help to construct the end-use service category consumption estimates.

Full and restricted forms of the model (Equation 1) are estimated. The restricted model is represented by Equation 1, with the time subscripts on the variable coefficients omitted. In this case, the structure of the model is assumed to be invariant with time. This assumption was empirically tested by using a likelihood ratio test. 
Rejection of the null hypothesis indicates a statistically significant change in the structural relationship between the set explanatory variables specified in the model and natural gas consumption and would, therefore, also imply a statistically significant change in natural gas intensity. There are many potential underlying causes for a structural shift in natural gas use. Within the context of the model specified in this paper, they may include changes in consumer preferences, age composition and labor market status of household members, real household income, the relative price of natural gas, end-use equipment technology, the thermal integrity and architectural characteristics of the home, the range of household services produced, geographic composition of the sample, or data collection methods. Whatever the reasons, structural changes may either result in an increase (augmenting) or a decrease (diminishing) in natural gas consumption. 


\section{DATA}

A series of RECS data files provided information for this study (DOE 1989a, 1993a, 1995a). ${ }^{3} \quad$ The sample sizes for the 1987, 1990, and 1993 RECS were 6,229, 5,095 , and 7,041, respectively.

The data for 1987,1990 , and 1993 were pooled and used to estimate the restricted model. For the pooled data set, some of the same residential addresses (not necessarily the same households, since households may have moved between survey years) were in the 1987 and 1990 data files. Those files contained a longitudinal survey that was discontinued in 1993.

TABLE 2 Household Population Estimates (thousands of households) and Number of Observations

\begin{tabular}{lrrr}
\hline & \multicolumn{3}{c}{ Year } \\
\cline { 2 - 4 } Income Quintile & 1987 & 1990 & 1993 \\
\hline Lowest & & & 19,220 \\
$\quad$ Household population & 18,100 & 18,790 & 1,420 \\
$\quad$ Observations & 1,462 & 1,033 & 19,220 \\
Middle & & & 1,339 \\
$\quad$ Household population & 18,110 & 18,780 & \\
$\quad$ Observations & 1,227 & 1,027 & 19,230 \\
Highest & & & 1,519 \\
$\quad$ Household population & 18,120 & 18,810 & \\
$\quad$ Observations & 1,101 & 983 & \\
\hline
\end{tabular}

Table 2 shows household population estimatesand the number of observations for each income group. As expected, the household population estimates are approximately the same for the three groups. The number of observations for the lowest-income quintile group is slightly higher in the 1987 and 1990 surveys, but slightly lower than that for the highest-income quintile group in 1993. Historically, the EIA has oversampled lowerincome households, with the support of the Division of Energy Assistance, Office of Community Services for Children and Families, U.S. Department of Health and Human Services.

Table 3 shows the natural gas consumption estimates for the lowest-, middle-, and highest-income quintiles for the three time periods. ${ }^{4}$ Interestingly, the differences in the

\footnotetext{
${ }^{3}$ For a general description of the RECS, see DOE 1993b, Appendix A, pp. 129-142.

${ }^{4}$ Because of the complicated survey design, the standard algebraic formula for computing variances cannot be used. The standard errors given in this table are derived from the column and row factors associated with natural gas consumption estimates for household categories with similar household population
} 
natural gas consumption estimates for the lowest- and middle-income quintile groups are statistically insignificant, but the estimates differ substantially from that for the highestincome quintile group. This pattern holds true for each of the three survey periods.

TABLE 3 Average Natural Gas Consumption $\left(10^{6} \mathrm{Btu} / \mathrm{yr} \text { per household }\right)^{\mathrm{a}}$

\begin{tabular}{ccccccc}
\hline & \multicolumn{3}{c}{ Year } & \multicolumn{3}{c}{ Percentage Change } \\
\cline { 2 - 7 } Income Quintile & 1987 & 1990 & 1993 & $1987-1990$ & $1990-1993$ & $1987-1993$ \\
\hline \multirow{2}{*}{ Lowest } & 49.25 & 44.01 & 46.59 & & & \\
& $(1.10)$ & $(1.00)$ & $(1.40)$ & -10.64 & 5.86 & -5.41 \\
Middle & 49.41 & 46.52 & 49.01 & & & \\
& $(1.10)$ & $(1.10)$ & $(1.40)$ & -5.85 & 5.35 & -0.81 \\
Highest & 66.49 & 69.11 & 68.48 & & & \\
& $(1.50)$ & $(1.60)$ & $(2.00)$ & 3.94 & -0.91 & 2.99 \\
\hline
\end{tabular}

${ }^{\mathrm{a}}$ Values in parentheses are estimated standard errors. These values were calculated using column and row factors reported in various EIA reports (DOE 1989b, 1993b, and 1995d). They were taken from tables reporting average natural gas consumption for household categories with household population estimates comparable to those for the income quintile groups. The relative standard error for the 1987 and 1990 estimates was about $2.3 \%$ and for the 1993 estimate about $2.9 \%$.

In all cases, the change in natural gas consumption between survey periods is statistically insignificant for each income group. The point estimates indicate that average natural gas consumption fell for the lowest- and middle-income quintiles and increased for the highest-income quintile between 1987 and 1990. Conversely, between 1990 and 1993, consumption rose for the lowest- and middle-income quintiles and fell slightly for the highest-income quintile. The 1990-to-1993 increase was not sufficient to bring natural gas consumption in 1993 back to its 1987 level for the lowest- and middle-income quintile groups; therefore, natural gas consumption fell during the entire 1987-to-1993 period. On the other hand, the decrease in natural gas consumption between 1990 and 1993 was not sufficient to drop 1993 natural gas consumption back to its 1987 level for the highestincome quintile. As a consequence, natural gas consumption rose slightly over the entire 1987-to-1993 period.

Averages of the energy-related variables included in this study are shown in Table 4 , where the data are broken down by income quintile and by year. All five of the variables shown in the table are hypothesized to be positively related to natural gas consumption.

The average number of heating degree days fell for each of the income classes between 1987 and 1990 . The decline ranged from $4.2 \%$ for the highest-income quintile to about $8.6 \%$ for the middle-income quintile. Between 1990 and 1993, a dramatic increase in the average number of heating degree days occurred for each of the income quintiles.

estimates. The row and column factors were obtained from DOE reports covering three surveys (DOE $1989 \mathrm{~b}, 1993 \mathrm{~b}, 1995 \mathrm{~d})$. For information on how the factors are used for calculating the standard errors, see any one of these reports. 
TABLE 4 Mean Value of Variables

\begin{tabular}{lcccccc}
\hline & \multicolumn{3}{c}{ Year } & \multicolumn{3}{c}{ Percentage Change } \\
\cline { 2 - 7 } Income Quintile & 1987 & 1990 & 1993 & $1987-1990$ & $1990-1993$ & $1987-1993$ \\
\hline Lowest & & & & & & \\
Heating Area (ft ${ }^{2}$ ) & 1,043 & 1,103 & 1,097 & 5.75 & -0.54 & 5.18 \\
Heating Degree Days ( $\mathrm{F}$ ) & 4,173 & 3,847 & 4,460 & -7.81 & 15.93 & 6.88 \\
Natural Gas Space Heat (\%) & 56 & 53 & 50 & -5.36 & -5.66 & -10.71 \\
Natural Gas Water Heat (\%) & 54 & 50 & 52 & -7.41 & 4.00 & -3.70 \\
Household Members & 2.07 & 2.12 & 2.11 & 2.42 & -0.47 & 1.93 \\
Single-Family Home (\%) & 51 & 52 & 50 & 1.96 & -3.85 & -1.96 \\
Middle & & & & & & \\
Heating Area (ft ${ }^{2}$ ) & 1,423 & 1,460 & 1,599 & 2.60 & 9.52 & 12.37 \\
Heating Degree Days ( $\left.{ }^{\circ} \mathrm{F}\right)$ & 4,290 & 3,922 & 4,643 & -8.58 & 18.38 & 8.23 \\
Natural Gas Space Heat (\%) & 54 & 53 & 50 & -1.85 & -5.66 & -7.41 \\
Natural Gas Water Heat (\%) & 53 & 51 & 48 & -3.77 & -5.88 & -9.43 \\
Household Members & 2.59 & 2.67 & 2.56 & 3.09 & -4.12 & -1.16 \\
Single-Family Home (\%) & 63 & 67 & 70 & 6.34 & 4.48 & 11.11 \\
Highest & & & & & & \\
Heating Area (ft ${ }^{2}$ ) & 2,105 & 2,278 & 2,246 & 8.21 & -1.40 & 6.70 \\
Heating Degree Days ( $\left.{ }^{\circ} \mathrm{F}\right)$ & 4,075 & 3,904 & 4,503 & -4.20 & 15.34 & 10.50 \\
Natural Gas Space Heat (\%) & 59 & 60 & 58 & 1.69 & -3.33 & -1.69 \\
Natural Gas Water Heat (\%) & 61 & 60 & 60 & -1.64 & 0.00 & -1.64 \\
Household Members & 3.05 & 3.04 & 3.11 & -0.33 & 2.30 & 1.97 \\
Single-Family Home (\%) & 85 & 85 & 88 & 0.00 & 3.53 & 3.53 \\
\hline
\end{tabular}

The increase ranged from $15.3 \%$ for the highest-income quintile to about $18.4 \%$ for the middle-income quintile.

As expected, the size of the area heated increases with income quintile. In each of the time periods, the average area heated for the highest-income quintile is more than double that of the lowest-income quintile. The average area heated for the middle-income quintile increased over both periods. For the lowest- and highest-income quintiles, the average area heated increased between 1987 and 1990 and then decreased slightly between 1990 and 1993.

As with area heated, the average number of household members increases with income quintile. Over time, the average number of household members has remained relatively stable for each income class. Between 1987 and 1990, the average number of household members increased slightly for the lowest- and middle-income quintiles and remained virtually the same for the highest-income quintile group. Between 1990 and 1993, it decreased slightly for the lowest- and middle-income quintile groups and increased slightly for the highest-income quintile group.

More than half of all households use natural gas for space and water heating. For the three income groups, the highest-income quintile has the largest natural gas share in the space-heating, end-use service category; in each of the periods, the natural gas space- 
heating share is larger for this group. Furthermore, the natural gas share remains relatively constant for the highest-income quintile. For the lowest- and middle-income quintiles, the natural gas space-heating share declines in each period.

In general, the natural gas water-heating shares are in the same range as the spaceheating shares. For the middle-income quintile, as was the case for space heating, the natural gas water-heating share falls in each time period. The share remains about the same for the highest-income quintile, whereas it fluctuates for the lowest-income quintile, falling between 1987 and 1990 and then rising between 1990 and 1993.

As well as differing in heating area size, single-family housing has other unique characteristics - higher ceilings and more walls exposed to outside surfaces - that affect energy consumption. Over the 1987-to-1993 period, the percentage of middle- and highest-income quintile households living in single-family homes increased. The increase in the number of middle-income quintile households living in single-family homes was particularly impressive; the percentage grew in each period. For the lowest-income quintile group, the percentage of households living in single-family homes remained relatively constant.

Table 5 summarizes changes in household natural gas consumption and energyrelated variables. Between 1987 and 1990, despite increases in heated area and number of household members, average household natural gas consumption fell for the lowestincome quintile group. The increases in heated area and number of household members were insufficient to offset the decline in natural gas space- and water-heating shares and in heating degree days for this group. Between 1990 and 1993, natural gas consumption rose, driven partly by increases in heating degree days and by an increase in the natural gas water-heating share.

Between 1990 and 1993, natural gas consumption increased for the middle-income quintile. Along with the increase in natural gas usage, both the area heated and the number of heating degree days increased for this group, whereas natural gas space- and water-heating, end-use service shares fell.

For the middle-income quintile, changes in energy-related variables between 1987 and 1990 were similar to those for the lowest-income quintile - the natural gas share in space and water heating, as well as heating degree days, all fell, as did natural gas consumption.

Over the three periods, the changes in household natural gas consumption for the highest-income quintile and for the two lower-income quintile groups moved in opposite directions - rising between 1987 and 1990 and falling between 1990 and 1993 for the highest-income quintile group. Between 1987 and 1990, the rise in natural gas consumption was accompanied by increases in area heated and natural gas space-heating share. Between 1990 and 1993, natural gas consumption fell, with an accompanying fall in natural gas space-heating share and area heated. 
Section 4 gives the results associated with the regression analysis used to estimate the natural gas consumption model (Equation 1). The major objective of this analysis is to more explicitly explain the changes in natural gas consumption. The analysis breaks down the changes in natural gas consumption into explanatory variable and structural factors. Of particular interest is the extent to which these changes vary by income class and over time.

TABLE 5 Qualitative Changes in Household Natural Gas Consumption and Related Variables

\begin{tabular}{lccc}
\hline Income Quintile & \multicolumn{3}{c}{ Change } \\
\hline Lowest & $1987-1990$ & $1990-1993$ & $1987-1993$ \\
\cline { 2 - 4 } Natural Gas Consumption & - & & - \\
Heating Area & + & - & + \\
Heating Degree Days & - & + & + \\
Natural Gas Space Heat & - & - & - \\
Natural Gas Water Heat & - & + & + \\
Household Members & + & - & + \\
Middle & & & + \\
Natural Gas Consumption & - & + & - \\
Heating Area & + & + & - \\
Heating Degree Days & - & - & - \\
Natural Gas Space Heat & - & - & + \\
Natural Gas Water Heat & - & - & + \\
Household Members & + & & + \\
Highest & + & - & - \\
Natural Gas Consumption & + & - & - \\
Heating Area & + & + & + \\
Heating Degree Days & - & + & + \\
Natural Gas Space Heat & + & - & + \\
Natural Gas Water Heat & - & + & + \\
Household Members & - & + & + \\
\hline
\end{tabular}




\section{ANALYSIS}

Restricted and unrestricted models were estimated for each of the three income classes. ${ }^{5}$ The restricted model was estimated by using a pooled data set consisting of each of the RECS surveys - 1987, 1990, and 1993. The unrestricted model was composed of separate equations estimated for each RECS. A log-likelihood test was used to test for the overall differences in the model structure across each of the RECS periods.

\subsection{RESTRICTED MODEL}

Table 6 gives the estimates for the restricted models. For each of the income classes, the determination of natural gas use strongly depends on space-heating use ng_heat. In each case, the natural-gas space-heat dummy is significant at the 0.005 level. Also significant are the cross effects of heating degree days and the area of the home heated (space_l), giving an estimate of the normalized effect of natural gas space heat on natural gas consumption with respect to heating degree days and number of household members.

Natural gas use for water heating is also an important determinant of natural gas consumption. Its effect on natural gas usage becomes more pronounced with a fall in temperature and a rise in the number of household members. The parameter (water_3) gives an estimated value of the normalized effect of water heating on natural gas consumption. In this case, the effect of water heating on consumption is also normalized with respect to number of household members and heating degree days.

The type of housing is also important in determining the level of natural gas consumption, particularly for the lowest- and middle-income quintile groups. In each case, living in a single-family dwelling has, as was hypothesized, a positive and significant effect on natural gas consumption. On average, it is estimated that living in a single-family home will increase natural gas consumption by about 7 million Btu/yr per household.

As indicated in Table 3, the level of natural gas consumption rises with income class. The difference in natural gas consumption between income groups depends not only on variable differences, but also on structural differences in the relationship between the explanatory variables and the dependent variable - natural gas consumption. An issue of interest is whether these relational differences are statistically significant and, if so, to what extent they may explain natural gas consumption differences between income classes.

\footnotetext{
${ }^{5}$ The models were estimated using the ordinary least-squares procedure in the SHAZAM Econometrics Computer Program (SHAZAM 1993).
} 
TABLE 6 Natural Gas Consumption Model Parameter Estimates for the Restricted Model

\begin{tabular}{|c|c|c|c|c|}
\hline \multirow[b]{2}{*}{ Variable } & \multicolumn{4}{|c|}{ Income Quintile } \\
\hline & Lowest & Middle & Highest & All \\
\hline \multirow[t]{2}{*}{ const } & $-1.96^{b}$ & $-2.70^{\circ}$ & 0.59 & $-1.98^{c}$ \\
\hline & $(0.92)$ & $(1.00)$ & $(1.89)$ & $(0.67)$ \\
\hline \multirow[t]{2}{*}{ ng_heat } & $36.04^{c}$ & $36.89^{\circ}$ & $45.56^{\circ}$ & $39.94^{c}$ \\
\hline & $(1.77)$ & $(1.90)$ & $(2.36)$ & (1.14) \\
\hline \multirow[t]{2}{*}{ space_1 } & $6.09 \times 10^{-6 \mathrm{c}}$ & $3.38 \times 10^{-6 \mathrm{c}}$ & $4.55 \times 10^{-6 c}$ & $5.12 \times 10^{-6 \mathrm{c}}$ \\
\hline & $\left(4.03 \times 10^{-7}\right)$ & $\left(4.11 \times 10^{-7}\right)$ & $\left(3.93 \times 10^{-7}\right)$ & $\left(2.20 \times 10^{-7}\right)$ \\
\hline \multirow[t]{2}{*}{ space_2 } & $-8.64 \times 10^{-70}$ & $4.15 \times 10^{-7} d$ & $-6.97 \times 10^{-7} \mathrm{c}$ & $-8.40 \times 10^{-7} \mathrm{c}$ \\
\hline & $\left(2.84 \times 10^{-7}\right)$ & $\left(2.45 \times 10^{-7}\right)$ & $\left(2.03 \times 10^{-7}\right)$ & $\left(1.22 \times 10^{-7}\right)$ \\
\hline \multirow[t]{2}{*}{ space_3 } & $1.59 \times 10^{-8}$ & $-1.04 \times 10^{-70}$ & $7.96 \times 10^{-8 c}$ & $7.66 \times 10^{-8 c}$ \\
\hline & $\left(4.03 \times 10^{-8}\right)$ & $\left(3.41 \times 10^{-8}\right)$ & $\left(2.41 \times 10^{-8}\right)$ & $\left(1.57 \times 10^{-8}\right)$ \\
\hline \multirow[t]{2}{*}{$n g \_h 2 o$} & 2.84 & $8.03^{\circ}$ & 4.01 & $2.60^{f}$ \\
\hline & $(3.10)$ & (3.27) & $(4.96)$ & $(2.01)$ \\
\hline \multirow[t]{2}{*}{ water_l } & 1.21 & 2.22 & $5.22^{b}$ & $5.57^{\circ}$ \\
\hline & $(2.28)$ & (1.95) & $(2.55)$ & $(1.19)$ \\
\hline \multirow[t]{2}{*}{ water_2 } & -0.01 & -0.18 & $-0.41^{f}$ & $-0.55^{\circ}$ \\
\hline & $(0.34)$ & $(0.24)$ & $(0.30)$ & $(0.15)$ \\
\hline \multirow[t]{2}{*}{ water_3 } & $2.47 \times 10^{-3 c}$ & $1.39 \times 10^{-3 \mathrm{c}}$ & $1.13 \times 10^{-3 c}$ & $1.48 \times 10^{-3 c}$ \\
\hline & $\left(1.66 \times 10^{-4}\right)$ & $\left(1.44 \times 10^{-4}\right)$ & $\left(1.50 \times 10^{-4}\right)$ & $\left(8.53 \times 10^{-5}\right)$ \\
\hline \multirow[t]{2}{*}{ singfam } & $7.20^{\circ}$ & $6.81^{\circ}$ & $2.42^{f}$ & $5.91^{\circ}$ \\
\hline & $(1.05)$ & $(1.09)$ & (1.88) & $(0.71)$ \\
\hline Observations & 3,915 & 3,593 & 3,603 & 11,111 . \\
\hline R-Square & 0.6840 & 0.7313 & 0.7148 & 0.7148 \\
\hline Log likelihood & $-46,401$ & $-42,282$ & $-43,336$ & $-132,249$ \\
\hline Likelihood ratio & $460^{c}$ & & & \\
\hline
\end{tabular}

${ }^{a}$ Standard error values are shown in the parentheses.

${ }^{b}$ Significant at the 0.025 level.

'Significant at the 0.005 level.

d Significant at the 0.05 level.

- Significant at the 0.01 level.

f Significant at the 0.1 level.

The data strongly indicate statistically significant differences in the natural gas consumption structure for the three income groups, thereby indicating that the overall quantitative effect of the explanatory variables on natural gas consumption is different for the three groups.

Of particular interest are the parameter estimates that normalize space- and waterheating loads (space_I and water_3 ) with respect to area heated and heating degree days, and to household size and heating degree days, respectively. In both cases, the parameter estimates for the lowest-income quintile are larger than the parameter estimates for either the middle- or highest-income quintile, possibly indicating that more intensive or lessefficient natural gas technologies (after normalization) are being used by the lowestincome quintile in producing space- and water-heating services. The estimate of the 
middle-income group's normalized space-heating parameter is smaller, whereas the estimate for its normalized water-heating parameter is larger.

Relative differences in natural gas intensity were determined, using the highestincome quintile as the reference group. The variable profile for the highest-income quintile group was used to estimate natural gas consumption for each income group, given the estimated structure for each specific group. A positive difference between the estimated level of natural gas consumption for the nonreference income quintile (either the lowest- or middle-income quintile group) and the highest-income quintile would imply a higher level of natural gas intensity for the nonreference income group, and a negative difference would imply a lower level of intensity.

For the restricted model, where it is assumed that the structure remains the same for each survey period, the analysis indicates that the production of household services for the lowest-income quintile is more natural gas intensive - and for the middle-income quintile, less natural gas intensive - compared with the highest-income quintile. The natural gas estimates by end-use category are presented in Table 7. As this table shows, the estimated differences by end-use service category vary widely and tend to cancel out when total use is examined. The end-use consumption estimates may be biased because of multicollinearity among the explanatory variables, so some caution should be exercised in interpreting the end-use consumption data in Table 7.

TABLE 7 Structural Difference Effects on Natural Gas Consumption: Restricted Model $\left(10^{6} \mathrm{Btu} / \mathrm{yr}\right.$ per household)

\begin{tabular}{lccccc}
\hline & \multicolumn{3}{c}{ Income Quintile } & \multicolumn{2}{c}{$\begin{array}{c}\text { Percentage Difference with } \\
\text { Highest-Income Quintile }\end{array}$} \\
\cline { 2 - 6 } End-Use & Lowest & Middle & Highest & Lowest & Middle \\
Category & 4.24 & 3.16 & 2.68 & 58.21 & 17.91 \\
\hline Base load & 42.86 & 43.04 & 47.09 & -8.98 & -8.60 \\
Space heat & 23.37 & 18.71 & 18.28 & 27.81 & 2.36 \\
Water heat & 70.46 & 64.91 & 68.05 & 3.55 & -4.61 \\
Total & & & & & \\
\hline
\end{tabular}

TABLE 8 Correlation Matrix of Coefficients ${ }^{\text {a }}$

\begin{tabular}{|c|c|c|c|c|c|c|c|c|c|c|}
\hline Variable & const & ng heat & space_l & space_2 & space_3 & $n g \_h 20$ & water_l & water_2 & water_3 & singfam \\
\hline const & 1.00 & -0.18 & 0.09 & -0.04 & 0.03 & -0.21 & 0.11 & -0.06 & -0.07 & -0.70 \\
\hline ng_heat & & 1.00 & -0.23 & 0.09 & -0.08 & -0.32 & -0.09 & 0.06 & 0.17 & 0.02 \\
\hline space_1 & & & 1.00 & -0.91 & 0.80 & -0.51 & 0.57 & -0.48 & -0.08 & -0.13 \\
\hline space_2 & & & & 1.00 & -0.95 & 0.54 & -0.61 & 0.59 & -0.05 & 0.05 \\
\hline space_3 & & & & & 1.00 & $-0,47$ & 0.61 & -0.64 & -0.05 & -0.04 \\
\hline$n g \_h 20$ & & & & & & 1.00 & -0.78 & 0.69 & -0.05 & 0.16 \\
\hline water_1 & & & & & & & 1.00 & -0.93 & -0.27 & -0.15 \\
\hline water_2 & & & & & & & & 1.00 & 0.09 & 0.08 \\
\hline water 3 & & & & & & & & & 1.00 & 0.12 \\
\hline singfam & & & & & & & & & & 1.00 \\
\hline
\end{tabular}

This matrix of correlation coefficients was generated with a model estimated using the entire 1987 to 1993 database and the observations on the lowest-, middle-, and highest-income quintile groups. 
For reference, the correlation matrix of coefficients generated for a model estimated using the entire 1987 to 1993 database and all the observations on the lowest-, middle-, and highest-income quintile groups is given in Table 8 . In this case, multicollinearity problems are likely to be less significant because of the larger number $(11,111)$ of observations. In many cases, the pairwise correlation coefficients are quite high. Very often, the correlations amiong the first three variables, which constitute the water-heating, end-use category ( $n g_{-} h 2 o$, water_l, and water_2), are quite high.

\subsection{UNRESTRICTED MODEL}

In the unrestricted model, it is no longer assumed that the structure for the natural gas consumption equation is the same for each survey period. The unrestricted model is composed of three separate equations, instead of one for each income group. Estimation of the unrestricted model involves estimating separate equations for each of the survey periods. The estimated models for each income group are discussed in Sections 4.2.14.2.3.

Table 9 shows the estimated end-use service fractions are shown for each income group by year. The most salient fact is the relative instability associated with the estimates of end-use share for the lowest-income quintile, where the space-heating, end-use share increases from $66 \%$ in 1987 to $78 \%$ in 1990 and then falls to $57 \%$ in 1993 , with nearly equal (but countervailing) changes in water-heating, end-use shares. On the other hand, the end-use shares for the middle- and highest-income quintile groups are relatively stable, with the space-heating, end-use share ranging around $68 \%$ and the water-heating, end-use share around $28 \%$.

TABLE 9 Percent Use by End-Use Service Category

\begin{tabular}{lrrr}
\hline & \multicolumn{3}{c}{ Year } \\
\cline { 2 - 4 } Income Quintile & 1987 & 1990 & 1993 \\
\hline Lowest & & & \\
Base load & 2.16 & 77.70 & 5.31 \\
Space heating & 66.35 & 19.51 & 57.45 \\
Water heating & 31.49 & & 37.25 \\
Middle & & 2.78 & \\
Base load & 4.98 & 68.07 & 3.54 \\
Space heating & 65.07 & 29.15 & 68.54 \\
Water heating & 29.95 &. & 27.92 \\
Highest & & 3.13 & \\
Base load & 3.97 & 70.37 & 68.36 \\
Space heating & 68.10 & 26.50 & 27.59 \\
Water heating & 27.93 & & \\
\hline
\end{tabular}




\subsubsection{Lowest-Income Quintile}

The parameter estimates for the natural gas model for the lowest-income quintile are shown in Table 10. For this income class, the proposition of a stable structure in natural gas use is strongly rejected. The data indicate that a significant change occurs over time in the structure of natural gas use by the lowest-income quintile group.

The model explains the variation in natural gas consumption reasonably well. In each of the survey periods, the model explains more than $65 \%$ of the total variance in natural gas consumption.

For each period, the natural gas space-heat ( $n g$ heat), natural gas space-heat normalized with respect to area heated and heating degree days (space_1), and natural gas water heat normalized with respect to the number of household members and heating degree days (water_3) are all statistically significant at the 0.005 level. The type of housing also is an important variable, with natural gas consumption significantly higher in single-family homes. On the average, it is estimated that the increase in natural gas consumption in single-family homes ranged from a little more than 5 million Btu/yr per household in 1987 and 1990 to slightly less than 10 million Btu/yr per household in 1993.

Table 11 shows estimates by end-use service category for each survey period after the effects of explanatory variable changes have been removed. In removing the influence of explanatory variable changes, an estimate can be generated for the change in natural gas intensity by end-use service category. ${ }^{6}$

For the lowest-income quintile, changes in natural gas intensity are not associated with any clear pattern of change. Between 1987 and 1990, it is estimated that overall natural gas consumption would fall as a result of natural gas intensity changes and then rise between 1990 and 1993. The estimates for space and water heating move in opposite directions. Between 1987 and 1990, natural gas consumption is estimated to rise in the space-heating, end-use service category and to fall dramatically in the water-heating, end-use service category as a result of changes in overall natural gas intensity. On the other hand, the opposite is estimated to happen between 1990 and 1993 . The structural shifts at the end-use service level are particularly dramatic between these two periods but tend to cancel out in the aggregate, leaving overall natural gas consumption relatively unchanged. Over the entire period, natural gas intensity in the space-heating, end-use service category is estimated to decline by almost $14 \%$.

\footnotetext{
${ }^{6}$ The method used to produce the income class estimates was also used to produce population-level estimates. The end-use consumption estimates were then compared with estimates provided in the EIA's 1993 RECS public-use data file and were found to be reasonably close. The EIA estimate the spaceheating share of household natural gas consumption to be higher - $73 \%$ vs. $65 \%$ - and its estimated water-heating share of household natural gas consumption to be lower $-26 \%$ vs. $29 \%$ (DOE 1995a).
} 
TABLE 10 Natural Gas Consumption Model Parameter Estimates for the Unrestricted Model: Lowest-Income Quintile

\begin{tabular}{|c|c|c|c|c|}
\hline \multirow[b]{2}{*}{ Variable } & \multicolumn{4}{|c|}{ Year } \\
\hline & 1987 & 1990 & 1993 & All \\
\hline \multirow[t]{2}{*}{ const } & -1.63 & -1.40 & $-2.44^{b}$ & $-1.96^{\circ}$ \\
\hline & $(1.55)$ & $(1.91)$ & $(1.36)$ & $(0.92)$ \\
\hline \multirow[t]{2}{*}{ ng_heat } & $33.16^{d}$ & $36.78^{d}$ & $32.68^{d}$ & $36.04^{d}$ \\
\hline & $(3.07)$ & $(3.65)$ & $(2.63)$ & $(1.77)$ \\
\hline \multirow[t]{2}{*}{ space_l } & $5.57 \times 10^{-6 d}$ & $4.32 \times 10^{-6 \mathrm{~d}}$ & $6.07 \times 10^{-6 d}$ & $6.09 \times 10^{-6 \mathrm{~d}}$ \\
\hline & $\left(6.88 \times 10^{-7}\right)$ & $\left(9.09 \times 10^{-7}\right)$ & $\left(6.27 \times 10^{-7}\right)$ & $\left(4.03 \times 10^{-7}\right)$ \\
\hline \multirow[t]{2}{*}{ space_2 } & $2.54 \times 10^{-8}$ & $1.26 \times 10^{-6 b}$ & $-1.18 \times 10^{-6}$ & $-8.64 \times 10^{-7 d}$ \\
\hline & $\left(4.94 \times 10^{-7}\right)$ & $\left(6.38 \times 10^{-7}\right)$ & $\left(4.88 \times 10^{-7}\right)$ & $\left(2.84 \times 10^{-7}\right)$ \\
\hline \multirow[t]{2}{*}{ space_3 } & $-4.65 \times 10^{-8}$ & $-2.03 \times 10^{-7}$ & $1.06 \times 10^{-8}$ & $1.59 \times 10^{-8}$ \\
\hline & $\left(6.79 \times 10^{-8}\right)$ & $\left(8.54 \times 10^{-8}\right)$ & $\left(7.50 \times 10^{-8}\right)$ & $\left(4.03 \times 10^{-8}\right)$ \\
\hline \multirow[t]{2}{*}{$n g \_h 2 o$} & $12.12^{c}$ & $11.52^{b}$ & -1.40 & 2.84 \\
\hline & $(5.35)$ & $(6.88)$ & (4.54) & (3.10) \\
\hline \multirow[t]{2}{*}{ water_l } & -1.91 & $-9.06^{b}$ & $6.75^{c}$ & 1.21 \\
\hline & $(4.00)$ & $(5.30)$ & $(3.24)$ & $(2.28)$ \\
\hline \multirow[t]{2}{*}{ water_2 } & 0.35 & $1.41^{b}$ & $-0.70^{f}$ & -0.01 \\
\hline & $(0.61)$ & $(0.82)$ & $(0.46)$ & $(0.34)$ \\
\hline \multirow[t]{2}{*}{ water_3 } & $2.29 \times 10^{-3 d}$ & $1.86 \times 10^{-3 d}$ & $2.58 \times 10^{-3 \mathrm{~d}}$ & $2.47 \times 10^{-3 \mathrm{~d}}$ \\
\hline & $\left(2.96 \times 10^{-4}\right)$ & $\left(3.75 \times 10^{-4}\right)$ & $\left(2.32 \times 10^{-4}\right)$ & $\left(1.66 \times 10^{-4}\right)$ \\
\hline \multirow[t]{2}{*}{ singfam } & $5.25^{\mathrm{d}}$ & $5.01^{e}$ & $9.88^{d}$ & $7.20^{d}$ \\
\hline & (1.71) & (2.14) & (1.63) & $(1.05)$ \\
\hline Observations & 1,462 & 1,033 & 1,420 & 3,915 \\
\hline R-Square & 0.6960 & 0.6581 & 0.7258 & 0.6840 \\
\hline Log likelihood & $-17,305$ & $-12,269$ & $-16,709$ & $-46,401$ \\
\hline Likelihood ratio & $236^{d}$ & & & \\
\hline
\end{tabular}

Standard error values are shown in the parentheses.

b Significant at the 0.05 level.

' Significant at the 0.025 level.

'Significant at the 0.005 level

' Significant at the 0.01 level

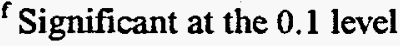

\subsubsection{Middle-Income Quintile}

As for the lowest-income quintile, the proposition of a stable structure is rejected for the middle-income quintile. Again, the model explains the variance in natural gas consumption well. For the middle-income quintile group, the R-square exceeds 0.70 in each of the survey periods.

For the middle-income group, the parameter estimates are shown in Table 12. As in the lowest-income quintile case, the natural gas space heat ( $n g$ heat), natural gas space 
TABLE 11 Estimated End-Use Consumption Due to Structural Changes: LowestIncome Quintile ( $10^{6} \mathrm{Btu} / \mathrm{yr}$ per household)

\begin{tabular}{lrrrrrr}
\hline & \multicolumn{3}{c}{ Year } & \multicolumn{3}{c}{ Percentage Change } \\
\cline { 2 - 7 } End Use & 1987 & 1990 & 1993 & $1987-1990$ & $1990-1993$ & $1987-1993$ \\
\hline Base load & 1.06 & 1.17 & 2.63 & 10.38 & 124.79 & 148.11 \\
Space heat & 32.68 & 35.46 & 28.21 & 8.51 & -20.45 & -13.68 \\
Water heat & 15.51 & 8.96 & 15.43 & -42.23 & 72.21 & -0.52 \\
Total & 49.25 & 45.59 & 46.28 & -7.43 & 1.51 & -6.03 \\
\hline
\end{tabular}

TABLE 12 Natural Gas Consumption Model Parameter Estimates for the Unrestricted Model: Middle-Income Quintile ${ }^{\mathrm{a}}$

\begin{tabular}{|c|c|c|c|c|}
\hline \multirow[b]{2}{*}{ Variable } & \multicolumn{4}{|c|}{ Year } \\
\hline & 1987 & 1990 & 1993 & All \\
\hline \multirow[t]{2}{*}{ const } & $-2.05^{b}$ & $-2.52^{b}$ & $-3.65^{c}$ & $-2.70^{d}$ \\
\hline & $(1.59)$ & $(1.65)$ & $(1.90)$ & $(1.00)$ \\
\hline \multirow[t]{2}{*}{ ng_heat } & $34.21^{\mathrm{d}}$ & $35.46^{d}$ & $40.48^{\mathrm{d}}$ & $36.89^{d}$ \\
\hline & $(2.95)$ & (3.13) & $(3.77)$ & $(1.90)$ \\
\hline \multirow[t]{2}{*}{ space_l } & $1.76 \times 10^{-6 \mathrm{~d}}$ & $3.71 \times 10^{-6 \mathrm{~d}}$ & $4.37 \times 10^{-6 \mathrm{~d}}$ & $3.38 \times 10^{-6 \mathrm{~d}}$ \\
\hline & $\left(6.78 \times 10^{-7}\right)$ & $\left(8.38 \times 10^{-7}\right)$ & $\left(4.23 \times 10^{-7}\right)$ & $\left(4.11 \times 10^{-7}\right)$ \\
\hline \multirow[t]{2}{*}{ space_2 } & $1.66 \times 10^{-6 d}$ & $1.27 \times 10^{-7}$ & $-2.47 \times 10^{-7}$ & $4.15 \times 10^{-7} \mathrm{c}$ \\
\hline & $\left(4.10 \times 10^{-7}\right)$ & $\left(5.09 \times 10^{-7}\right)$ & $\left(4.23 \times 10^{-7}\right)$ & $\left(2.45 \times 10^{-7}\right)$ \\
\hline \multirow[t]{2}{*}{ space_3 } & $-2.59 \times 10^{-7 d}$ & $-2.39 \times 10^{-8}$ & $-6.06 \times 10^{-8}$ & $-1.04 \times 10^{-7 d}$ \\
\hline & $\left(5.52 \times 10^{-8}\right)$ & $\left(7.18 \times 10^{-8}\right)$ & $\left(6.20 \times 10^{-8}\right)$ & $\left(3.41 \times 10^{-8}\right)$ \\
\hline \multirow[t]{2}{*}{$n g \_h 2 o$} & $15.46^{\mathrm{d}}$ & $13.68^{\mathrm{e}}$ & -6.01 & $8.03^{6}$ \\
\hline & $(4.90)$ & $(5.99)$ & $(6.55)$ & $(3.27)$ \\
\hline \multirow[t]{2}{*}{ water_l } & -1.17 & -1.27 & $9.85^{e}$ & 2.22 \\
\hline & $(2.91)$ & $(3.72)$ & $(4.08)$ & (1.95) \\
\hline \multirow[t]{2}{*}{ water_2 } & 0.14 & 0.03 & $-0.80^{b}$ & -0.18 \\
\hline & $(0.31)$ & $(0.49)$ & $(0.53)$ & $(0.24)$ \\
\hline \multirow[t]{2}{*}{ water_3 } & $1.32 \times 10^{-3 d}$ & $1.54 \times 10^{-3 \mathrm{~d}}$ & $1.33 \times 10^{-3 \mathrm{~d}}$ & $1.39 \times 10^{-3 \mathrm{~d}}$ \\
\hline & $\left(2.47 \times 10^{-4}\right)$ & $\left(2.50 \times 10^{-4}\right)$ & $\left(2.58 \times 10^{-4}\right)$ & $\left(1.44 \times 10^{-4}\right)$ \\
\hline \multirow[t]{2}{*}{ singfam } & $7.15^{d}$ & $5.72^{\mathrm{d}}$ & $7.72^{d}$ & $6.81^{\mathrm{d}}$ \\
\hline & $(1.73)$ & $(1.78)$ & $(2.09)$ & $(1.09)$ \\
\hline Observations & 1,227 & 1,027 & 1,339 & 3,593 \\
\hline R-Square & 0.7473 & 0.7645 & 0.7027 & 0.7313 \\
\hline Log likelihood & $-14,352$ & $-11,934$ & $-15,949$ & $-42,282$ \\
\hline Likelihood ratio & $94^{\mathrm{d}}$ & & & \\
\hline \multirow{2}{*}{\multicolumn{5}{|c|}{ a Standard error values are shown in the parentheses. }} \\
\hline & & & & \\
\hline \multirow{2}{*}{\multicolumn{5}{|c|}{$\begin{array}{l}\text { Significant at the } 0.05 \text { level. } \\
\text { d Significant at the } 0.005 \text { level. }\end{array}$}} \\
\hline & & & & \\
\hline \multicolumn{5}{|c|}{${ }^{\mathrm{e}}$ Significant at the 0.025 level } \\
\hline \multicolumn{5}{|c|}{${ }^{f}$ Significant at the 0.01 level } \\
\hline
\end{tabular}


heat normalized with respect to area heated and heating degree days (space_1), and natural gas water-heating normalized with respect to the number of household members and heating degree days (water_3), as well as the single-family dummy variable coefficient, are all statistically significant at the 0.005 level for the middle-income quintile.

In Table 13, middle-income quintile household natural gas consumption estimates are shown by end-use service category for each of the survey periods. The structure of natural gas consumption for the middle-income quintile is relatively stable in comparison to the structure for the lowest-income quintile. This fact is reflected in that the changes at the end-use service category and aggregate levels do not fluctuate as widely as they do for the lowest-income quintile group.

From Table 12, note that in each period, the coefficients associated with the ng_heat and space_l variables increase. This growth closely translates into the observed increase, albeit a small one, in the estimated level of natural gas consumption in the spaceheating, end-use service category seen in Table 13, which arises because of changes in natural gas intensity. Conversely, the estimated change in natural gas consumption in the water-heating, end-use area falls between each survey period. Total natural gas consumption is estimated to decrease slightly for the middle-income quintile group in each survey period.

For the entire six-year period, natural gas consumption is estimated to fall slightly, declining by $2.11 \%$ because of changes in natural gas intensity. Natural gas consumption is estimated to decline - by $6.22 \%$ - in the water-heating, end-use service category and to rise - by $3.51 \%$ - in the space-heating, end-use service category as a result of natural gas intensity.

\subsubsection{Highest-Income Quintile}

As in the two lower income groups, the hypothesis of a stable structure for natural gas consumption is rejected for the highest-income quintile. Again, the specified model explains variation in natural gas consumption rather accurately, with the $\mathrm{R}$-square exceeding 0.70 in each period. The parameter estimates for the highest-income quintile group are shown in Table 14.

For the highest-income quintile, the single-family home dummy variable is relatively insignificant compared with that for the lowest- and middle-income quintile groups. The natural gas space-heating dummy variable is the most important explanatory variable in the model. As in the other cases, the natural gas space-heating (normalized with respect to area heated and heating degree days) and natural gas water-heating (normalized with respect to the number of household members and heating degree days) variables are also important. Unlike the lowest- and middle-income quintile cases, the statistical significance of these variables differs between survey periods. In the 1987 
TABLE 13 Estimated End-Use Consumption Due to Structural Changes: MiddleIncome Quintile $\left(10^{6}\right.$ Btu/yr per household)

\begin{tabular}{lrrrrrr}
\hline & \multicolumn{3}{c}{ Year } & \multicolumn{3}{c}{ Percentage Change } \\
\cline { 2 - 7 } End Use & 1987 & 1990 & 1993 & $1987-1990$ & $1990-1993$ & $1987-1993$ \\
\hline Base load & 2.46 & 1.09 & 1.22 & -55.69 & 11.93 & -50.41 \\
Space heat & 32.15 & 32.99 & 33.28 & 2.61 & 0.88 & 3.51 \\
Water heat & 14.80 & 14.47 & 13.88 & -2.23 & -4.08 & -6.22 \\
Total & 49.41 & 48.55 & 48.37 & -1.74 & -0.37 & -2.11 \\
\hline
\end{tabular}

TABLE 14 Natural Gas Consumption Model Parameter Estimates for the Unrestricted Model: Highest-Income Quintile"

\begin{tabular}{|c|c|c|c|c|}
\hline \multirow[b]{2}{*}{ Variable } & \multicolumn{4}{|c|}{ Year } \\
\hline & 1987 & 1990 & 1993 & All \\
\hline const & $\begin{array}{l}-4.87^{b} \\
(3.10)\end{array}$ & $\begin{array}{l}5.30^{b} \\
(3.62)\end{array}$ & $\begin{array}{c}0.52 \\
(3.15)\end{array}$ & $\begin{array}{c}0.59 \\
(1.89)\end{array}$ \\
\hline ng_heat & $\begin{array}{l}50.55^{\mathrm{C}} \\
(3.61)\end{array}$ & $\begin{array}{l}39.37^{\circ} \\
(4.78)\end{array}$ & $\begin{array}{l}45.79^{\circ} \\
(4.03)\end{array}$ & $\begin{array}{l}45.56^{\circ} \\
(2.36)\end{array}$ \\
\hline space_l & $\begin{array}{l}1.78 \times 10^{-6 d} \\
\left(9.37 \times 10^{-7}\right)\end{array}$ & $\begin{array}{l}2.83 \times 10^{-6 c} \\
\left(8.06 \times 10^{-7}\right)\end{array}$ & $\begin{array}{l}5.95 \times 10^{-6 \mathrm{c}} \\
\left(5.56 \times 10^{-7}\right)\end{array}$ & $\begin{array}{l}4.55 \times 10^{-6} \mathrm{c} \\
\left(3.93 \times 10^{-7}\right)\end{array}$ \\
\hline space_2 & $\begin{array}{l}7.92 \times 10^{-7} \mathrm{~b} \\
\left(5.67 \times 10^{-7}\right)\end{array}$ & $\begin{array}{l}6.90 \times 10^{-76} \\
\left(4.37 \times 10^{-7}\right)\end{array}$ & $\begin{array}{l}-1.60 \times 10^{-6} c \\
\left(2.68 \times 10^{-7}\right)\end{array}$ & $\begin{array}{c}-6.97 \times 10^{-7} \mathrm{c} \\
\left(2.03 \times 10^{-7}\right)\end{array}$ \\
\hline space_3 & $\begin{array}{c}-1.30 \times 10^{-7} \mathrm{~d} \\
\left(7.47 \times 10^{-8}\right)\end{array}$ & $\begin{array}{l}-7.99 \times 10^{-7} b \\
\left(5.69 \times 10^{-8}\right)\end{array}$ & $\begin{array}{c}1.78 \times 10^{-7} \\
\left(2.99 \times 10^{-8}\right)\end{array}$ & $\begin{array}{l}7.96 \times 10^{-8} 6 \\
\left(2.41 \times 10^{-8}\right)\end{array}$ \\
\hline$n g \_h 2 o$ & $\begin{array}{l}13.88^{\mathrm{b}} \\
(10.13)\end{array}$ & $\begin{array}{l}15.40^{\mathrm{d}} \\
(9.34)\end{array}$ & $\begin{array}{l}-2.99 \\
(7.93)\end{array}$ & $\begin{array}{c}4.01 \\
(4.96)\end{array}$ \\
\hline water_l & $\begin{array}{l}-3.41 \\
(5.83)\end{array}$ & $\begin{array}{c}4.56 \\
(4.74)\end{array}$ & $\begin{array}{l}6.55^{d} \\
(3.87)\end{array}$ & $\begin{array}{l}5.22^{b} \\
(2.55)\end{array}$ \\
\hline water_2 & $\begin{array}{c}0.45 \\
(0.80)\end{array}$ & $\begin{array}{l}-0.26 \\
(0.57)\end{array}$ & $\begin{array}{c}-0.55^{\mathrm{b}} \\
(0.42)\end{array}$ & $\begin{array}{c}-0.41^{b} \\
(0.30)\end{array}$ \\
\hline water_3 & $\begin{array}{l}1.75 \times 10^{-3} \mathrm{c} \\
\left(2.61 \times 10^{-4}\right)\end{array}$ & $\begin{array}{c}3.60 \times 10^{-4} \\
\left(3.42 \times 10^{-4}\right)\end{array}$ & $\begin{array}{c}1.39 \times 10^{-3} \mathrm{c} \\
\left(2.12 \times 10^{-4}\right)\end{array}$ & $\begin{array}{l}1.13 \times 10^{-3} \mathrm{c} \\
\left(1.50 \times 10^{-4}\right)\end{array}$ \\
\hline singfam & $\begin{array}{l}8.86^{c} \\
(3.00)\end{array}$ & $\begin{array}{l}-3.68^{b} \\
(3.62)\end{array}$ & $\begin{array}{c}2.80 \\
(3.16)\end{array}$ & $\begin{array}{l}2.42^{b} \\
(1.88)\end{array}$ \\
\hline Observations & 1,101 & 983 & 1,519 & 3,603 \\
\hline R-Square & 0.7440 & 0.7099 & 0.7156 & 0.7148 \\
\hline $\begin{array}{l}\text { Log likelihood } \\
\text { Likelihood ratio }\end{array}$ & $\begin{array}{c}-13,070 \\
164^{c}\end{array}$ & $-11,834$ & $-18,350$ & $-43,336$ \\
\hline
\end{tabular}

${ }^{\mathrm{a}}$ Standard error values are shown in the parentheses.

${ }^{\mathrm{b}}$ Significant at the 0.1 level.

${ }^{\circ}$ Significant at the 0.005 level.

${ }^{\mathrm{d}}$ Significant at the 0.05 level.

'Significant at the 0.025 level. 
survey period, the normalized natural gas space-heating variable is not highly significant but it is statistically significant at the 0.005 level in the other two survey periods. The normalized natural gas water-heating variable is relatively unimportant in the 1990 survey period but is statistically significant at the 0.005 level in the other two survey periods.

Table 15 gives the estimates for end-use natural gas consumption because of structural changes for the highest-income quintile. Between 1987 and 1990, estimated overall natural gas consumption rises slightly, and between 1990 and 1993 it falls. In contrast to the two lower-income groups, the changes in estimated natural gas consumption in the space- and water-heating, end-use categories move, between periods, in the same direction, rising slightly between 1987 and 1990 and falling between 1990 and 1993.

Between 1987 and 1993, total natural gas consumption is estimated to fall by about $4 \%$ because of changes in natural gas intensity. The estimated natural gas consumption in the space- and water-heating, end-use service categories falls for the highest-income quintile: 3.6 and $6.6 \%$ in the space- and water-heating areas, respectively.

\subsubsection{Structural and Variable Decomposition}

Figure 1 shows the structural and variable decomposition of changes in natural gas consumption between 1987 and 1990. Between these two surveys, the model indicates that structural and variable changes were reinforcing. For the two lower income quintiles, both variable and structural changes contributed to a decrease in natural gas consumption, whereas for the highest-income quintile, they contributed to an increase.

The natural gas intensity-related decline in natural gas consumption is largest for the lowest-income quintile, which is largely explained by the estimated structural change within the water-heating, end-use service category. More than $65 \%$ of the total decline in natural gas consumption between 1987 and 1990 in the lowest-income quintile is explained by structural shifts in natural gas use. The remainder is explained by explanatory variable changes.

The structural fraction of the overall change in middle-income natural gas consumption is more modest than that for the lowest-income quintile. Between 1987 and 1990 , structural shifts only accounted for only slightly more than $30 \%$ of the total decline in natural gas consumption.

The highest-income quintile, unlike the lower-income quintile groups, experienced a growth in natural gas consumption between 1987 and 1990. Both structural and variable changes contributed to this growth. It is estimated that explanatory variable changes constituted a dominant share of the change in natural gas consumption between 1987 and 1990 for the highest-income quintile, with an estimated more than $60 \%$ of the change in natural gas consumption due to explanatory variable changes. 
TABLE 15 Estimated End-Use Consumption Due to Structural Changes: HighestIncome Quintile $\left(10^{6} \mathrm{Btu} / \mathrm{yr}\right.$ per household)

\begin{tabular}{lrrrrrr}
\hline & \multicolumn{3}{c}{ Year } & \multicolumn{3}{c}{ Percentage Change } \\
\cline { 2 - 7 } End Use & 1987 & 1990 & 1993 & $1987-1990$ & $1990-1993$ & $1987-1993$ \\
\hline Base load & 2.64 & 2.19 & 2.90 & -17.05 & 32.42 & 9.85 \\
Space heat & 45.28 & 46.13 & 43.63 & 1.88 & -5.42 & -3.64 \\
Water heat & 18.57 & 18.89 & 17.35 & 1.72 & -8.15 & -6.57 \\
Total & 66.49 & 67.21 & 63.87 & 1.08 & -4.97 & -3.94 \\
\hline
\end{tabular}

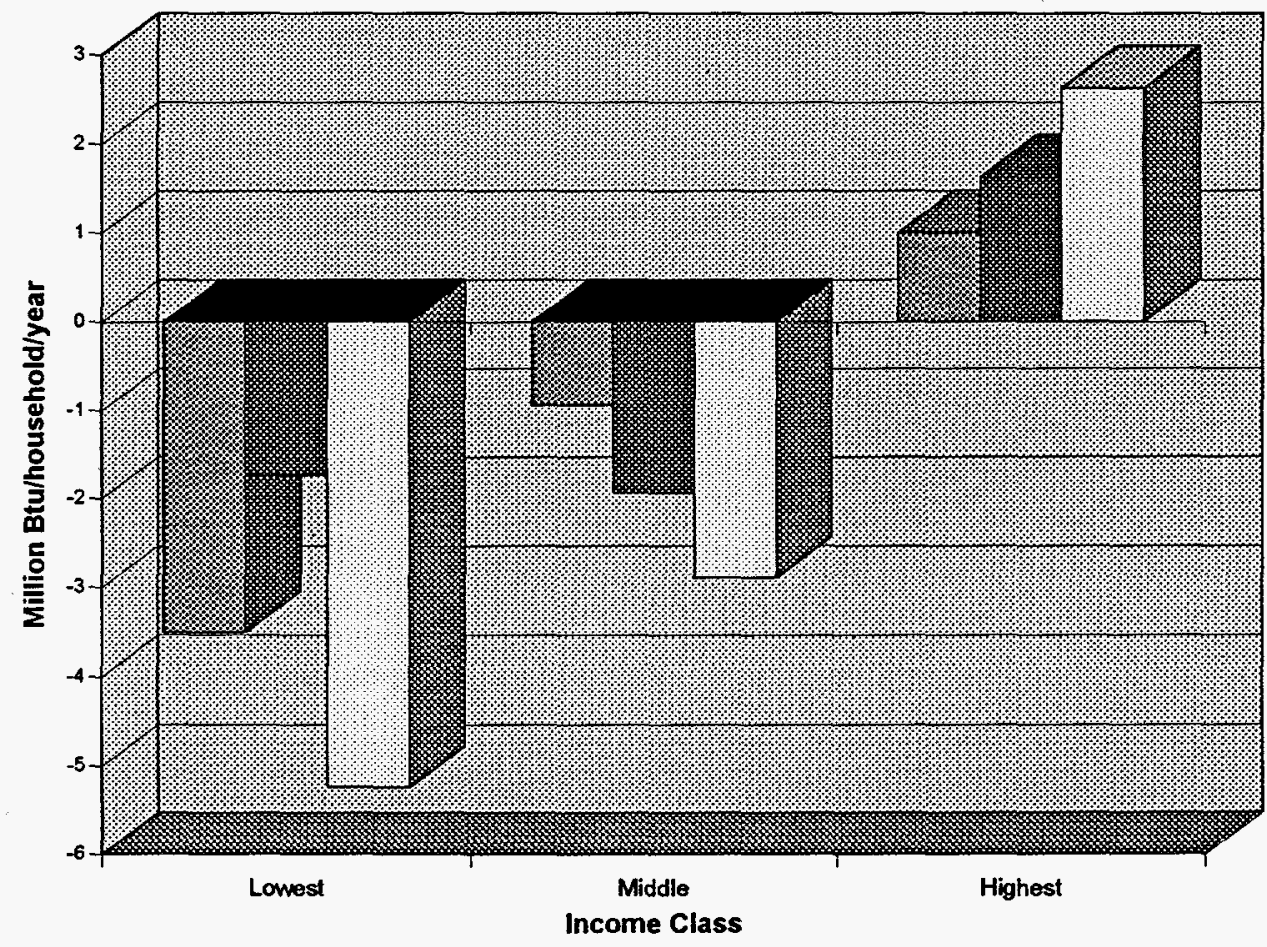

S structural

variable

Qtotal

FIGURE 1 Decomposition of Changes in Natural Gas Consumption: 1987-1990 


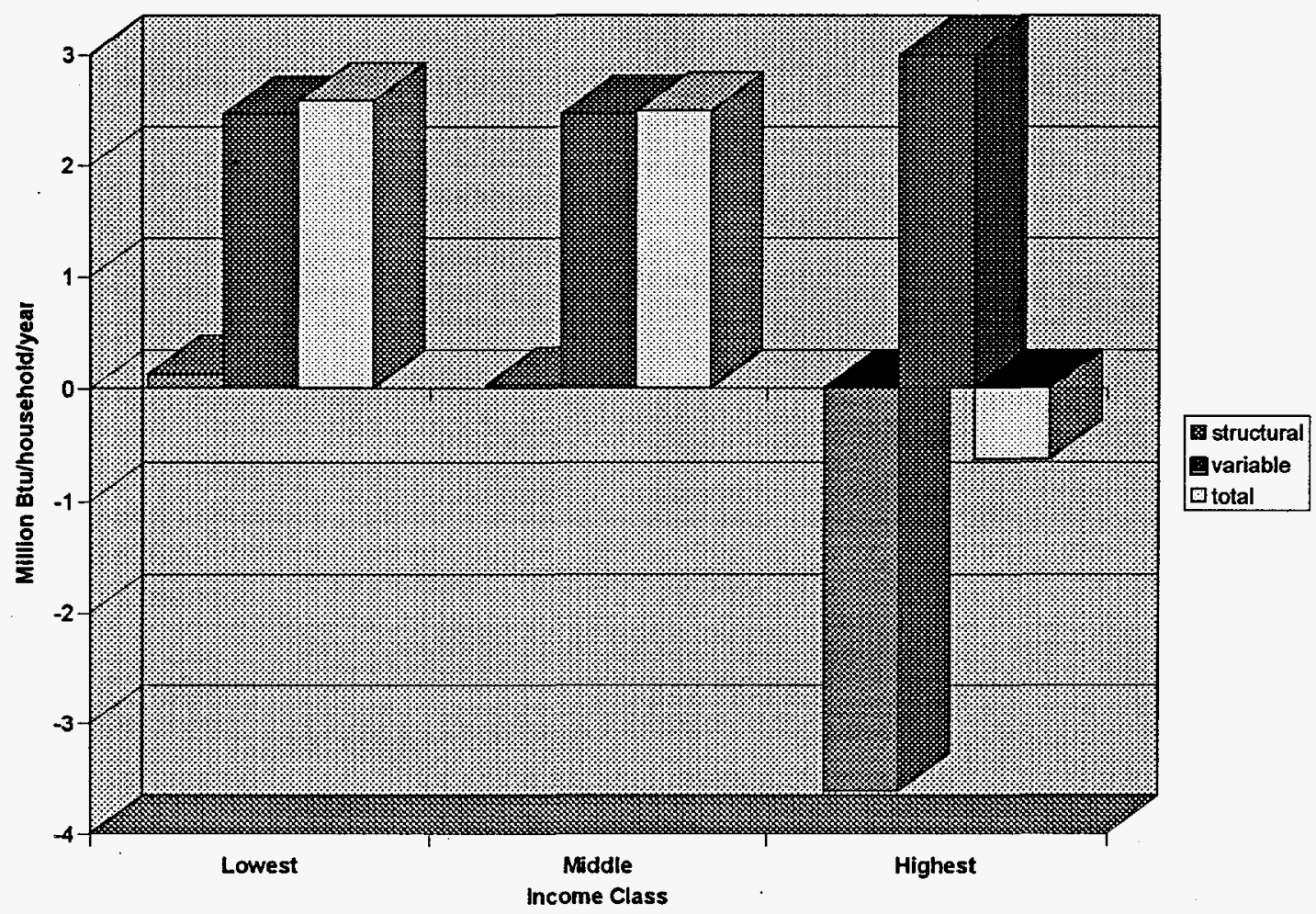

FIGURE 2 Decomposition of Changes in Natural Gas Consumption: 1990-1993

Figure 2 shows the decomposition of changes in natural gas consumption into structural and variable components from 1990 to 1993. Over that period, natural gas consumption increases for the lowest- and middle-income quintile groups, while falling slightly for the highest-income group. For the lowest- and middle-income quintile groups, the increase in natural gas consumption is almost entirely driven by explanatory variable changes, with little or no change attributable to structural shifts.

For the highest-income quintile group, there is a small decline in natural gas consumption between 1990 and 1993, with the variable and structural components having counterbalancing effects: the structural effects reduce natural gas consumption while the variable effects increase consumption. The structural effects are estimated to reduce the average level of natural gas consumption by about 4 million Btu/yr per household, whereas the variable effects increase it by about 3 million Btu/yr per household. 


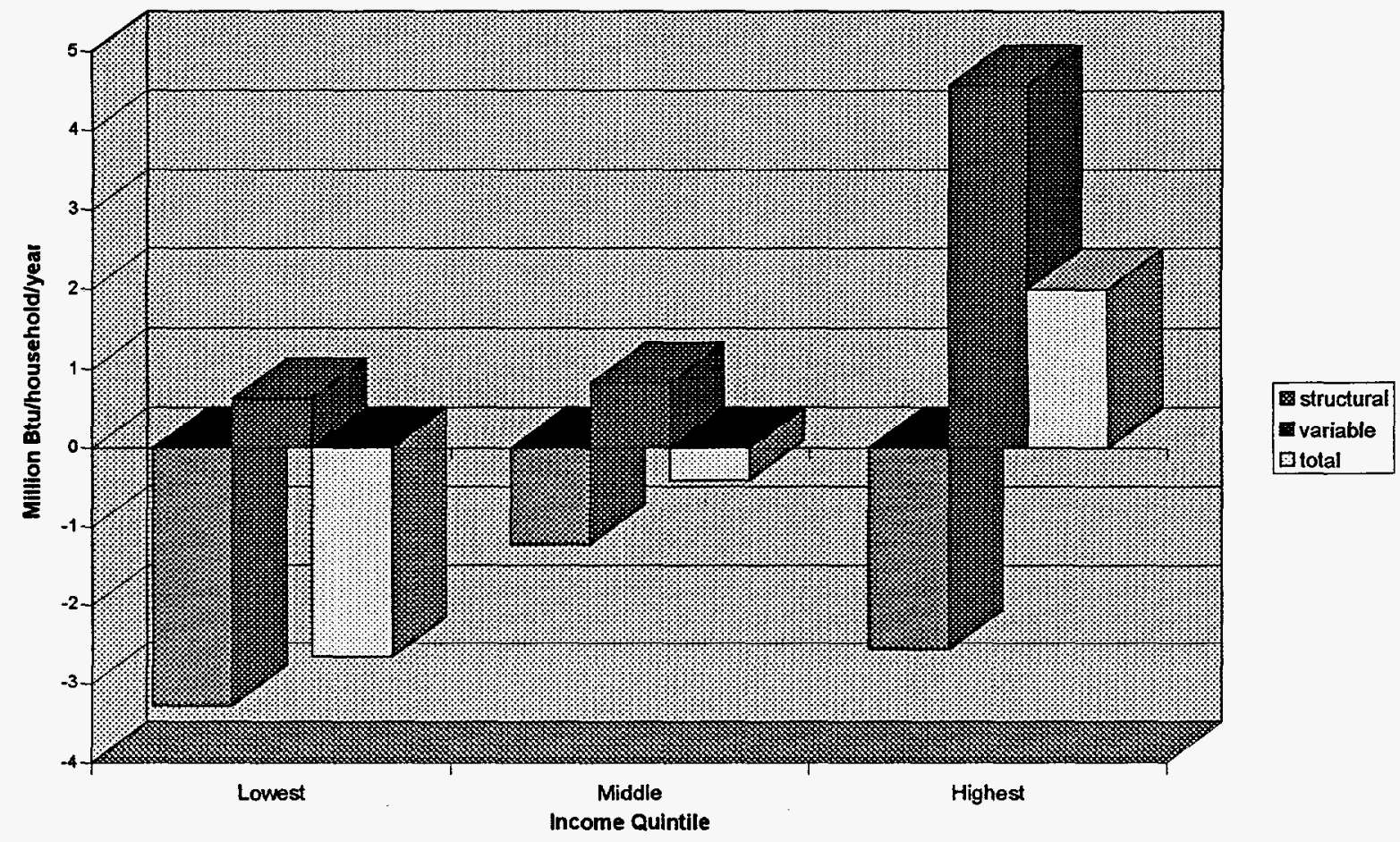

FIGURE 3 Decomposition of Changes in Natural Gas Consumption: 1987-1993

Figure 3 shows the decomposition of total natural gas consumption change into structural and explanatory variable changes. For each of the three income groups, it is estimated that natural gas consumption declines as a result of structural changes in natural gas use and increases as a result of explanatory variable changes. However, natural gas consumption is estimated to fall only for the lowest- and middle-income quintiles, and the fall for the middle-income quintile is very small.

The entire estimated fall in natural gas consumption is due to a fall in natural gas intensity; in the absence of this fall, natural gas consumption would actually have increased. Between 1987 and 1993, it is estimated that natural gas consumption fell by more than 3.3 million Btu/yr per household because of a decline in natural gas intensity; without the decline, natural gas consumption would have increased by 0.6 million Btu/yr per household for the lowest-income quintile group.

For the middle-income quintile group, estimated natural gas consumption declined slightly. As for the lowest-income quintile, it is estimated that the net effect of changes in explanatory variables on natural gas consumption would have been positive. Estimated 
savings in natural gas consumption due to changes in natural gas intensity are over one million Btu/yr per household for middle-income quintile households.

For the highest-income quintile, natural gas consumption is estimated to have increased between 1987 and 1993. However, it is estimated that all of the increase was due to changes in explanatory variables. It is estimated that, if it were not for changes in explanatory variables, natural gas consumption would have fallen for the highest-income quintile group by over 2.5 million Btu/yr per household.

\subsubsection{Comparative Analysis}

The preceding analysis primarily assesses temporal changes within each income group. This section presents a comparative analysis across groups. The purpose of this analysis is to provide some insight into the reasons behind changes in natural gas consumption. It might be inferred that the extent to which relative changes in the structure lead to changes in natural gas consumption makes a group's welfare more or less vulnerable to sudden changes in natural gas demand indicators and, in particular, to sudden weather changes. It also provides some guide for policy in that it helps to identify the effect of explanatory variable changes on natural gas consumption and confidence in the stability of the relationship between natural gas use and the variables that affect it. Moreover, such an analysis provides some evidence of the relative impact that past energy-related policies and programs have had on natural gas consumption by these population groups.

Tto compare the relative impacts of changes in the structure of natural gas use on natural gas consumption, the explanatory variable profile for the highest-income quintile group was used to estimate natural gas consumption for the two lower-income groups (while holding their respective structures constant). The natural gas consumption estimates for the lowest- and middle-income quintiles were then compared with that for the highest-income quintile. The results of this analysis are shown in Table 16.

In general, the differences between the lowest- and highest-income quintiles vary more widely. In the space-heating, end-use service category, the differences range from -26 to $20 \%$, and in the water-heating area, from $-28 \%$ to $56 \%$. The variation is primarily driven by relatively large changes, as discussed earlier, in the estimated structure for the lowest-income group. Therefore, in the end-use service category, inferences about the directional effect of structural differences on natural gas consumption, between the lowest- and highest-income quintiles, depend on the reference year. For example, the data indicate the consumption of natural gas within the space-heating, end-use service category by the lowest-income group is higher in 1987, and substantially higher in 1990, than that of the highest-income group because of structural differences, but it is considerably lower in 1993. 
TABLE 16 Estimated Percentage Difference in End-Use Consumption Due to Structural Differences with the Highest-Income Quintile

\begin{tabular}{lrrr}
\hline End-use Consumption/ & \multicolumn{1}{c}{ Year } \\
\cline { 2 - 4 } Income Quintile & 1987 & 1990 & 1993 \\
\hline Base load & & & \\
Lowest & 7.00 & 33.17 & 109.38 \\
Middle & 51.73 & 9.39 & 4.87 \\
Space heat & & & \\
Lowest & 6.19 & 20.44 & -26.02 \\
Middle & -6.63 & -7.95 & -9.78 \\
Water heat & & & \\
Lowest & 27.95 & -27.98 & 56.08 \\
Middle & -1.47 & -6.36 & 11.15 \\
Total & & & \\
Lowest & 12.30 & 8.01 & 2.53 \\
Middle & -2.87 & -6.99 & -3.37 \\
\hline
\end{tabular}




\section{CONCLUSIONS}

The analysis of the 1987, 1990, and 1993 RECS data strongly indicates statistically significant differences in the structure of natural gas use over time and among income groups. The relative importance of the structural and variable factors, in explaining natural gas consumption changes between survey periods, varies by income group. Between 1987 and 1990, structural changes in natural gas use are relatively more important in the lowest- and middle-income quintile groups, whereas the structure in natural gas use remains relatively unchanged between 1990 and 1993.

For the highest-income quintile, the change in the structure of natural gas use moves in different directions - increasing natural gas consumption between 1987 and 1990 and decreasing natural gas consumption between 1990 and 1993.

The statistical evidence also suggests that the use of natural gas by the middleincome quintile is less intensive, and that by the lowest-income quintile more intensive, than that by the highest-income quintile. The differences in natural gas intensities indicate the lowest-income quintile is the most vulnerable to sudden changes in demand indicators/explanatory variables that lead to a rise in natural gas consumption. Therefore, to the extent that there is a social commitment to insulate vulnerable groups from the exigencies of severe weather, targeting assistance to lower-income groups seems appropriate.

Between 1987 and 1993, the greatest reduction in natural gas intensity was achieved in the water-heating, end-use service category. In this area, the reductions were largest for the middle- and highest-income quintile groups. This occurrence is not particularly surprising, given the relatively short time frame - from 1987 to 1993 - over which the analysis was done. Since the expected useful life of water-heating equipment is shorter than that of space-heating equipment, it can be anticipated that the stock of water-heating equipment will turn over more rapidly. Therefore, a shorter time horizon will reflect a relatively greater penetration of newer and more natural gas-efficient, waterheating equipment in the water-heating, end-use service area compared with the spaceheating, end-use service area where the expected equipment life is longer.

The data also indicate substantial improvement over time in space-heating, end-use natural gas intensities in the lowest-income quintile group. Between 1987 and 1993, it is estimated real improvement was achieved in the natural gas intensities for the lowestincome quintile group when compared with the highest-income quintile group. The improvement may reflect the success of energy conservation programs targeting the poor. The turnover in housing stock may also play a role, with natural gas consumption in lower-income households being disproportionately reduced as a result of the turnover in housing stock and heating equipment. It is safe to speculate that in 1993, a relatively 
larger fraction of lower-income households lived in housing built between 1973 and 1988 than did so in 1987 , compared with higher-income households.

The analysis presented in this report has a major shortcoming - its failure to take into account the influence of economic variables on household energy consumption behavior. Future research in this area needs to concentrate on developing better methods for separating engineering and technological effects from behavioral effects. In particular, both the short- and long-run effects of prices and income must be taken into account. 


\section{REFERENCES}

SHAZAM User's Reference Mamual Version 7.0, 1993, McGraw-Hill Book Company, Inc., New York, N.Y.

U.S. Department of Energy, 1983, Regression Analysis of Energy Consumption by End Use, DOE/EIA-0431, Energy Information Administration, Washington, D.C.

U.S. Department of Energy, 1989a, Residential Energy Consumption Survey 1987, public-use data tape, Energy Information Administration, Washington, D.C.

U.S. Department of Energy, 1989b, Household Energy Consumption and Expenditure 1987, DOE/EIA-0321(87), Energy Information Administration, Washington, D.C.

U.S. Department of Energy, 1993a, Residential Energy Consumption Survey 1990, public-use data tape, Energy Information Administration, Washington, D.C.

U.S. Department of Energy, 1993b, Household Energy Consumption and Expenditure 1990, DOE/EIA-0321(90), Energy Information Administration, Washington, D.C.

U.S. Department of Energy, 1995a, Residential Energy Consumption Survey 1993, public-use data tape, Energy Information Administration, Washington, D.C.

U.S. Department of Energy, 1995b, Annual Energy Outlook 1995, DOE/EIA-0383(95), Energy Information Administration, Washington, D.C.

U.S. Department of Energy, 1995c, Measuring Energy Efficiency in the United States' Economy: A Beginning, DOE/EIA-0555(95)/2, Energy Information Administration, Washington, D.C.

U.S. Department of Energy, 1995d, Household Energy Consumption and Expenditure 1993, DOE/EIA-0321(93), Energy Information Administration, Washington, D.C.

U.S. Department of Energy, 1995e, Buildings and Energy in the 1980's, DOE/EIA0555(95)/1, Energy Information Administration, Washington, D.C. 